•研究报告・

\title{
复合污染尾矿废水中真菌群落多样性及其驱动机制
}

刘晋仙(1) ${ }^{*}$, 柴宝峰(11, 罗正明(1) 1,2

1. 山西大学黄土高原研究所, 黄土高原生态恢复山西省重点实验室, 太原 030006; 2. 忻州师范学院地理系, 山西忻州 034000

摘要: 金属尾矿废水中含有重金属以及多种有机和无机污染物, 然而在该极端生境中仍然有大量微生物存在。为了揭示碱性 尾矿废水中真菌群落的组成模式和多样性格局及其维持机制, 本文利用ITS1区rDNA基因扩增子测序和qPCR技术对山西中 条山十八河尾矿库废水中5个不同采样点真菌群落的组成、丰度和分布格局进行了研究。通过主坐标分析(PCoA)比较不同采 样点间群落结构的差异性; 通过圥余分析(RDA)探讨了水体理化因子对真菌群落结构的影响; 通过零模型分析了影响群落结 构的主要因素; 通过网络图分析了真菌类群之间的种间相互作用。结果表明，布勒掷狍酵母属(Bullera)、Schizangiella、支顶 孢属(Acremonium)和亚罗酵母属(Yarrowia)是主要的优势属, 真菌群落在不同采样地点从门到属水平的相对丰度均有明显变 化。真菌群落丰度沿水流方向逐渐增加且与有机碳(TOC)浓度呈显著正相关。真菌群落的 $\alpha$-多样性与 $\mathrm{pH}$ 、重金属(As和Cu)、 无机碳(IC)和铵态氮 $\left(\mathrm{NH}_{4}^{+}\right)$浓度显著相关。真菌群落的空间结构在不同采样点具有明显差异, 这种差异性与理化因子没有显著 关系; 不同采样点真菌群落的零偏差值均大于零, 且不同物种之间存在复杂的种间相互作用。以上结果说明, 在尾矿废水中 环境因子只对真菌群落的 $\alpha$-多样性有显著影响, 而群落的 $\beta$-多样性主要受种间相互作用关系的影响, 表明在碱性铜尾矿废水 中存在比较复杂的真菌群落动态模式。

关键词: 尾矿废水; 真菌群落; 多样性; 维持机制

刘晋仙, 柴宝峰, 罗正明 (2021) 复合污染尾矿废水中真菌群落多样性及其驱动机制. 生物多样性, 29, 373-384. doi: 10.17520/biods.2020181. Liu JX, Chai BF, Luo ZM (2021) Driving forces and the diversity of fungal communities in complex contaminated tailings drainage. Biodiversity Science, 29, 373-384. doi: 10.17520/biods.2020181.

\section{Driving forces and the diversity of fungal communities in complex contaminated tailings drainage}

Jinxian Liu ${ }^{\left({ }_{1 *}\right.}$, Baofeng Chai ${ }^{\left(\mathbb{D}_{1}\right.}$, Zhengming Luo ${ }^{\mathbb{D}_{1,2}}$

1 Institute of Loess Plateau, Shanxi University, Shanxi Key Laboratory of Ecological Restoration on Loess Plateau, Taiyuan 030006 2 Department of Geography, Xinzhou Teachers University, Xinzhou, Shanxi 034000

\begin{abstract}
Aims: Metal tailings drainage contains heavy metals and a variety of organic and inorganic pollutants, but a large number of microorganisms still exist in this extreme habitat. In order to reveal the composition pattern and diversity maintaining mechanism of fungal communities in alkaline copper mine drainage, the composition, abundance and distribution pattern of fungal communities in five water sites in Shibahe tailings reservoir were studied by using the rDNA gene amplification sequencing and qPCR in ITS1 area.

Methods: The fungal community compositions among different sample points were compared by principal coordinate analysis (PCoA). The relationship between physicochemical factors and the distribution of fungal communities were analyzed by redundancy analysis (RDA). The main factors influencing community structure were analyzed by null model. The interactions between fungal genera were analyzed by network.

Results: the results showed that Bullera, Schizangiella, Acremonium and Yarrowia were the dominant genera. The relative abundance of fungal communities varied significantly from phylum to genus level in different sampling sites. The abundance of fungal communities increased gradually along the direction of water flow and was positively
\end{abstract}

收稿日期: 2020-04-30; 接受日期: 2020-07-10

基金项目: 国家自然科学基金(31801962)和山西省基础研究项目(201901D211129; 201901D211457)

* 通讯作者 Author for correspondence. E-mail: liujinxian@sxu.edu.cn 
correlated with the concentration of total organic carbon (TOC). PH, heavy metals (As and $\mathrm{Cu}$ ), inorganic carbon (IC) and ammonium nitrogen $\left(\mathrm{NH}_{4}^{+}\right)$were significantly correlated with the $\alpha$-diversity of the communities. The distribution of fungal communities in different sample sites was obviously different. The physicochemical factors had no significant effect on the distribution of fungal community. The null deviation values of fungal communities in different sampling sites were greater than zero, and there were complex interactions among different genera.

Conclusions: These results indicated that the environmental factors only have a significant correlation with the $\alpha$-diversity of the fungal communities, while the $\beta$-diversity was mainly affected by the interaction between species in tailings drainage. Our findings highlight that there is a relatively complex fungal community dynamic pattern in alkaline copper tailings drainage.

Key words: tailings drainage; fungal communities; diversity; maintenance mechanism

矿石在湿法冶炼过程中产生大量尾矿废水, 金 属尾矿废水中含有多种污染物, 包括重金属和多种 有机以及无机浮悬剂。由于尾矿废水中污染物质成 分多样, 构成了复杂的复合污染系统。尾矿废水会 对周边的农田、河流以及地下水等造成了不同程度 的影响(贺梦醒等, 2011), 最终影响人类健康, 因此 对尾矿废水治理是恢复生态学的重要议题。尾矿废 水这样的极端环境通常被认为不适合大多数生物 生长(Newsham, 2012), 例如在酸性或碱性尾矿废水 中存在极端 $\mathrm{pH}$ 水平和较高浓度的重金属, 这些生 境似乎接近了生物活动的极限。然而在现实中, 虽 然这些极端的环境并不是多种生物的理想栖息地, 但是它们的生物多样性却比预期的高。极端生境作 为一个确定的、极具物种篮选力的生境, 是生物多 样性的重要来源, 为生物实现特殊适应机制创造了 有利条件。研究表明, 适应性较强、种类多样的微 生物在酸性(Baker \& Banfield, 2003; Sun et al, 2016) 和碱性(Bier et al, 2015; Liu et al, 2018)尾矿废水中 均有分布。尾矿废水的污染梯度对微生物群落组成 和结构有明显的分拣效应, 在高污染区域微生物群 落组成、结构和多样性发生了明显变化, 且微生物 生物量和活性明显降低(Bier et al, 2015)。已有的对 尾矿废水微生物群落适应性的研究大多针对的是 细菌群落, 对真菌群落的研究还非常有限 (马燕和 余晓斌, 2017), 尤其是在碱性尾矿废水中, 真菌群 落的多样性和适应机制的研究还未见报道。

真菌是地球上几乎所有生态系统都普遍存在 的重要微生物组分之一, 它们具有较高的系统发育 和功能多样性。除了在极端高温和深层地下生物圈 外(Newsham, 2012), 几乎在任何有能量来源的极端 条件下都能找到真菌群落的身影, 如极地苔原
(Osono et al, 2012)、深海底泥(Nagano et al, 2010; Jebaraj et al, 2010)、重金属污染土壤(Li et al, 2012)、 干旱河谷(Dreesens et al, 2014)以及尾矿废水(马燕 和余晓斌, 2017)等多种极端环境。通过环境篎选在 尾矿废水中存活下来的那些真菌类群, 具有适应其 生境的生长策略。这些真菌类群通过一系列的生化 反应在水质净化和生态环境恢复过程中发挥着重 要作用, 如降解有机污染物、络合重金属等, 且较 细菌的作用更强(Iram et al, 2009)。同时, 真菌的菌 丝体可为细菌群落提供附着位点, 形成生物膜, 从 而提高彼此的适应性。微生物群落组成、结构和空 间分布格局的变化可反映其生境的改变, 因此研究 尾矿废水中真菌群落组成和多样性格局的变化可 表征水体的污染程度。在不同极端环境中影响真菌 群落组成和分布的因素存在差异(Newsham, 2012), 在酸性土壤和水体中 $\mathrm{pH}$ 梯度是引起真菌群落组成 和多样性发生变化的最主要的因素(Glassman et al, 2017; Aguilera \& González-Toril, 2019), 但是在碱性 尾矿废水这样的复合污染环境中真菌群落的分布 模式和适应策略目前还不清楚。

中条山铜矿是北方最大的铜生产基地, 为全国 最大的金属地下开采矿山。在矿山采选、矿石冶炼 过程中有大量含有多种重金属的尾矿废水和废渣 产生, 由于浮悬剂硫化钠、中和剂碱石灰以及其他 有机试剂在浮悬过程中的使用, 使得尾矿中有机化 合物、硫化物含量过高且呈碱性。本研究选择不同 采样点尾矿废水中的真菌群落为研究对象, 探讨北 方铜尾矿废水中: (1)真菌群落的组成和空间分布格 局; (2)驱动这种分布格局形成的主要因素。旨在阐 明在金属尾矿废水中真菌群落的多样性维持机制, 为废水污染程度与微生物群落多样性格局的相互 
影响研究提供新的数据支持, 同时为不同污染区域 的生态修复提供理论依据。

\section{材料与方法}

\section{1 研究区概况}

中条山铜矿基地是我国的六大铜基地之一, 储 量占全国5\%以上。本研究的采样地点位于山西省垣 曲县的十八河尾矿库, 该尾矿库担负隶属于中条山 有色金属集团的铜矿峪矿选厂以及篦子沟矿选厂 尾矿的咜存任务, 建成于1972年4月, 目前已使用 48年。现已筑15级子坝, 每道子坝高 $5 \mathrm{~m}$, 坝顶长度 $1,714.8 \mathrm{~m}$, 坝高 $85 \mathrm{~m}$, 面积 200 万 $\mathrm{m}^{2}$, 最大库容 1.25 亿 $\mathrm{m}^{3}$, 目前库容 1 亿 $\mathrm{m}^{3}$, 汇水面积约 $54.6 \mathrm{~km}^{2}$ 。该宅 矿库是选矿废水和废渣的永久咜存地点, 为保证尾 矿库的安全在上端坝体设有渗流孔, 下端坝体设有 防洪洞, 因此尾矿库坝体上下两端均有废水渗流到 尾矿库外面。该区域属大陆性季风气候, 四季分明, 春季干旱多风, 夏季雨量集中, 冬季少雪干燥。

\section{2 样地设置与样品采集}

在尾矿库中间区域沿水流方向从上游到下游 设置了 3 个采样点(STW1、STW2和STW3), 在尾矿 库上下两端设置了 2 个渗流水采样点 (SUSW 和 SDSW)。利用自动水样采集器(W2BC-9600)收集水 样, 取样深度距表层 $1 \mathrm{~m}$ 。每个样品取水 $2 \mathrm{~L}$, 每个采 样点取3个重复, 样品采集于2016年9月。水样在原 地通过 $0.2 \mu \mathrm{m}$ 的微孔滤膜(Millipore, 津膡, 天津)过 滤用于收集水体微生物, 后将滤膜置于便携式液氮 罐中, 用于后续微生物基因组提取。过滤后的水带 回实验室用于理化参数的分析, 所有测试分析在 1 个月内完成。

\subsection{DNA提取、荧光定量PCR和高通量测序}

利用Fast DNA SPIN (MP Biomedicals, Santa Ana, CA, USA) 试剂盒, 参照说明书提取滤膜上微 生物的DNA, 提取好的DNA样品测定浓度和纯度 后分别进行苂光定量PCR扩增和一般PCR扩增。扩 增真菌的ITS1区片段。用酶标仪(Infinite M200 PRO, Tecan, Switzerland)测定DNA模板和质粒的浓度, 然 后稀释到 $10 \mathrm{ng} / \mu \mathrm{L}$ 后进行荧光定量PCR扩增(CFX96, BioRad, USA)。引物序列为ITS1F (5'-CTTGGTCAT TTAGAGGAAGTAA-3') 和ITS2R (5'-GCTGCGTTC TTCATCGATGC-3') (Orgiazzi et al, 2012), 每个反应
体系包括 $10 \mu \mathrm{L}$ SYBR ${ }^{\circledR}$ Premix Ex Taq $^{\mathrm{TM}}$ (Tli RNaseH Plus) (TaKaRa, Dalian, China), 前后引物各 $1 \mu \mathrm{L}(10 \mu \mathrm{M}), 1 \mu \mathrm{L}$ 的DNA模板, 然后用无菌水补至 $20 \mu \mathrm{L}$ 。PCR反应过程包括: $95^{\circ} \mathrm{C}$ 预变性 $3 \mathrm{~min}$, 扩增 (条件: $95^{\circ} \mathrm{C} 20 \mathrm{~s}, 58^{\circ} \mathrm{C} 30 \mathrm{~s}, 72^{\circ} \mathrm{C} 30 \mathrm{~s}$ ), 共 40 个循环; 最后添加溶解曲线, 每个循环增加 $0.5^{\circ} \mathrm{C} / \mathrm{s}$, 从 $65^{\circ} \mathrm{C}-95^{\circ} \mathrm{C}$ 用来分析PCR产物是否特异。通过将已知 拷贝数的质粒按 10 倍梯度连续稀释后进行定量PCR 便可获得标准曲线，从而获得目的基因的拷贝数, 质粒的拷贝数梯度是 $10^{3}-10^{8}$ ，扩增效率是 $98.5 \%$ 。 质粒的制备过程参照Liu等(2018)描述的方法进行, 一般PCR扩增体系参照刘晋仙等(2019)的方法。 PCR扩增产物通过胶回收纯化后在Illumina MiSeq 测序平台上进行高通量测序。

\section{4 生物信息学分析}

测序得到的原始双端序列数据, 使用 fastp和 FLASH软件进行质控优化。删除尾部质量值在20以 下、长度小于 $50 \mathrm{bp}$ 以及含 $\mathrm{N}$ 碱基的序列; 将有重叠 区的成对序列拼接成一条序列, 最小重叠区长度为 $10 \mathrm{bp}$; 拼接序列的重叠区允许的最大错配比率为 0.2 ; 根据序列首尾两端的标签和引物区分样品, 并 调整序列方向, 标签允许的错配数为 0 , 最大引物 错配数为 2 , 将序列分配到不同样品。优化后的序列 按 $97 \%$ 的相似性使用 Usearch version 7.0 软件 (http://drive5.com/uparse/) 进行可操作分类单元 (operational taxonomic units, OTUs)聚类, 将所有优 化序列与OTU代表序列比对, 选出与代表序列相似 性在 $97 \%$ 以上的序列, 生成OTU表格, 每个OTU中 数量最多的序列为代表序列; 以UNITE Release 7.2 (http://unite.ut.ee/index.php) 真菌数据库为参考对 OTU序列进行比对鉴定，通过RDP Classifier软件 (https://sourceforge.net/projects/rdp-classifier/)对序列 分类注释，获得物种的分类信息，物种分类的置信 度为 0.7 。本研究测序的样品中获得 382,717 条高质 量序列, 平均序列长度为 $259 \mathrm{bp}$; 对得到的高质量 序列, 按最小样本序列数抽平 $(63,438)$ 用于后续的 $\alpha$ 多样性和 $\beta$ 多样性分析。在Mothur version 1.30.2软 件 (https://www.mothur.org/wiki/Download_mothur) 中计算群落的 $\alpha$ 多样性指数, 如Chao1丰度估计、 Shannon和Simpson多样性指数以及盖度。本研究的 测序和生物信息服务在上海派森诺生物科技有限 公司完成。 


\section{5 理化性质分析}

水体 $\mathrm{pH}$ 、溶解氧 $(\mathrm{DO})$ 、电导率 $(\mathrm{EC})$ 、硝态氮 $\left(\mathrm{NO}_{3}^{-}\right)$和铵态氮 $\left(\mathrm{NH}_{4}^{+}\right)$含量通过便携式水质检测仪 (Aquread AP-2000, UK) 原位测定; 总碳(TC)、总有 机碳 (TOC) 和无机碳 (IC) 含量用 TOC 分析仪 (Shimadzu, TOC- $\mathrm{V}_{\mathrm{CPH}}$, Japan)测定; 亚硝态氮( $\left.\mathrm{NO}_{2}^{-}\right)$ 和硫酸盐 $\left(\mathrm{SO}_{4}^{2-}\right)$ 含量用全自动间断化学分析仪 (DeChem-Tech, CleverChem380, Germany)测定; 所 有重金属(As、Cd、Cu、Pb、Zn)含量用ICP-AES (iCAP 6000, Thermo Fisher, UK)测定。

\section{6 数据分析}

在分析之前对不符合正态分布的 $\mathrm{NO}_{2}^{-} 、 \mathrm{NH}_{4}^{+}$以 及所有重金属数据进行平方根转换, 对 TOC和IC数 据进行对数转换。不同采样点间的水体理化参数和 真菌拷贝数的差异在SPSS 20.0 (IBM SPSS, USA) 中采用 One-way ANOVA 分析, 并通过 Waller-Duncan进行组间比较; $\alpha$-多样性指数与环境 参数的相关性通过Spearman相关系数检验; 在 CANOCO version 5.0软件中通过主坐标分析(PCoA) 比较不同采样点之间的群落相似性, 并通过vegan $\mathrm{R}$ 软件包中的非参数多元分析 (PERMANOVA) 函数 检验分组间差异; 在CANOCO中首先通过前选择 (interactive forward selection)䇥选出对优势类群和 群落结构有显著影响的因子, 然后通过咒余 (redundancy analysis)分析不同环境因子对群落结构 的影响程度; 根据Tucker等(2016)和Chase等(2011) 构建的 $\beta$-零偏差值来定量分析确定性过程和随机过 程在群落构建中的相对重要性, $\left[\left(\beta_{\text {obs }}-\beta_{\text {null }}\right) / \beta_{\text {null }}\right]$ 偏 离零表示群落的构建是确定性过程决定的, 正值表 示种间相互作用, 负值表示环境选择, 接近零表示 随机过程在群落构建中起决定作用; 不同物种之间 的种间关系强弱通过Spearman相关系数表示, 在网 络构建过程中只保留相关系数 $r>0.6$, 且 $P<0.05$ 的 数值, 并通过Gephi version 0.9.2软件可视化。所有 统计分析的置信区间均为 $95 \%(P<0.05)$ 。

\section{2 结果}

\section{1 尾矿废水的理化性质}

$\mathrm{pH} 、 \mathrm{NO}_{3}^{-}$和 $\mathrm{NO}_{2}^{-}$浓度在 $S T W 1$ 中最大, 且显著 高于STW3、SDSW和SUSW (表1)。pH、EC、 $\mathrm{NO}_{3}^{-}$、 $\mathrm{NO}_{2}^{-}$和 $\mathrm{SO}_{4}^{2-}$ 沿着水流方向形成明显的梯度:
STW1 $>$ STW2 $>$ STW3。DO、TC、TOC和IC浓度 在 STW3 最大, 表现为沿水流方向增加的趋势 (STW1 < STW2 < STW3), 且尾矿库内水中EC、 $\mathrm{SO}_{4}^{2-} 、 \mathrm{NH}_{4}^{+} 、 \mathrm{TC}$ 和TOC浓度与下游渗流水(SDSW) 中的浓度显著不同。重金属As、Cu和Zn的浓度在不 同采样点也存在差异(表1)。

\section{2 真菌群落组成与分类鉴定}

在STW1、STW2、STW3、SUSW和SDSW这5 个采样点中, 真菌群落的原始序列数在STW2最小, 在 SUSW最大; OTU个数分别为 $404.67 、 118.66$ 、 499.58、460.05和237.33; Chao1指数与OTUs具有相 似的变化趋势, 也是在 STW3 最大, 在 STW2最小 (表2)。5 个采样点的Shannon指数分别为 $5.49 、 2.39$ 、 5.09、2.98和 2.58; Simpson指数与Shannon指数的变 化趋势也有相似性, 同样也是在STW1最大而在 STW2最小。5个采样点的盖度值(coverage)均大于 0.99 , 表明测序样品的真菌群落可代表该区域真实 的真菌群落(表2)。ITS rDNA的拷贝数变化代表真菌 群落丰度的变化, 真菌群落的丰度从上游(STW1) 到下游(STW3)逐渐增多, 且差异显著 $(P<0.01)$, 在 SUSW采样点真菌群落的拷贝数最小(图1)。

真菌群落隶属于子囊菌门、担子菌门、被孢霉 门、隐真菌门、毛霉菌门和壶菌门6 个已命名的门 以及未鉴定类群(图2)。在门水平, 真菌群落在 5 个采 样点均有分布, 但是它们的相对丰度存在差异: 在 SDSW中子囊菌门的相对丰度最高(92.99\%); 担子 菌门的相对丰度在SUSW中最高(70.17\%); 被孢霉 门在STW3中的相对丰度最高(7.08\%); 在STW2中 多数类群属于未分类群 $(80.64 \%)$ 。

在 5 个采样点中, 优势纲(相对丰度 > 1\%)共 12 个, 平均相对丰度为 $70.68 \%$; 优势目共 15 个, 平均 相对丰度为 $70.55 \%$; 优势科共 11 个, 平均相对丰度 为 $51.75 \%$; 优势属共 19 个, 平均相对丰度为 $49.60 \%$ (图3)。在STW1和SUSW中相对丰度最大的属均是 隶属于担子菌门银耳目银耳纲的布勒掷孢酵母属 (Bullera), 其相对丰度分别为 $31.84 \%$ 和 $68.43 \%$; 在 STW2中隶属于被孢霉门被狍霉目被狍霉纲的被狍 霉属(Mortierella)相对丰度最大, 为1.79\%; 在STW3 中隶属于子囊菌门肉座菌目粪壳菌纲的支顶狍属 (Acremonium) 的相对丰度最大, 为 $15.25 \%$; 在 SDSW中隶属于酵母菌目酵母菌纲子囊菌门的亚罗 酵母属(Yarrowia)相对丰度最大, 为 $41.57 \%$ (图3)。 
表1 不同采样点水体理化参数(平均值土标准误) $(\mathbf{n}=3)$

Table 1 Water physical and chemical parameters in different sample sites (mean \pm SE) $(n=3)$

\begin{tabular}{|c|c|c|c|c|c|}
\hline \multirow{2}{*}{$\begin{array}{l}\text { 因子 } \\
\text { Parameter }\end{array}$} & \multicolumn{5}{|c|}{ 采样点 Sample site } \\
\hline & STW1 & STW2 & STW3 & SUSW & SDSW \\
\hline$\overline{\mathrm{pH}}$ & $9.382 \pm 0.095^{\mathrm{a}}$ & $9.131 \pm 0.053^{\mathrm{a}}$ & $8.147 \pm 0.048^{\mathrm{b}}$ & $8.190 \pm 0.032^{b}$ & $8.014 \pm 0.076^{\mathrm{b}}$ \\
\hline 溶解氧 DO (mg/L) & $8.560 \pm 0.195^{\mathrm{a}}$ & $10.218 \pm 0.466^{\mathrm{a}}$ & $10.661 \pm 0.527^{\mathrm{a}}$ & $10.643 \pm 0.281^{\mathrm{a}}$ & $11.114 \pm 3.292^{\mathrm{a}}$ \\
\hline 电导率 EC (uS/cm) & $1,834.333 \pm 31.205^{\mathrm{a}}$ & $1,832.001 \pm 20.466^{\mathrm{a}}$ & $865.143 \pm 3.106^{b}$ & $1,427.333 \pm 59.218^{\mathrm{ab}}$ & $404.333 \pm 8.511^{\mathrm{c}}$ \\
\hline 硝态氮 $\mathrm{NO}_{3}^{-}(\mathrm{mg} / \mathrm{L})$ & $134.373 \pm 5.417^{\mathrm{a}}$ & $85.170 \pm 1.553^{\mathrm{ab}}$ & $14.315 \pm 1.142^{\mathrm{bc}}$ & $5.265 \pm 0.345^{c}$ & $4.698 \pm 0.364^{c}$ \\
\hline 亚硝态氮 $\mathrm{NO}_{2}^{-}(\mathrm{mg} / \mathrm{L})$ & $10.548 \pm 0.405^{\mathrm{a}}$ & $6.959 \pm 0.20^{\mathrm{ab}}$ & $1.259 \pm 0.096^{\mathrm{bc}}$ & $0.575 \pm 0.057^{c}$ & $0.478 \pm 0.044^{\mathrm{c}}$ \\
\hline 铵态氮 $\mathrm{NH}_{4}^{+}(\mathrm{mg} / \mathrm{L})$ & $1.453 \pm 0.003^{\mathrm{ab}}$ & $1.715 \pm 0.019^{\mathrm{a}}$ & $0.340 \pm 0.116^{\mathrm{b}}$ & $2.333 \pm 0.030^{\mathrm{a}}$ & $0.387 \pm 0.015^{\mathrm{b}}$ \\
\hline 总碳 TC (mg/L) & $20.600 \pm 0.035^{c}$ & $24.723 \pm 0.818^{\mathrm{bc}}$ & $34.523 \pm 3.215^{\mathrm{ab}}$ & $25.070 \pm 0.023^{\mathrm{bc}}$ & $52.315 \pm 0.136^{\mathrm{a}}$ \\
\hline 总有机碳 TOC (mg/L) & $7.597 \pm 0.003^{\mathrm{abc}}$ & $8.520 \pm 1.529^{\mathrm{bc}}$ & $14.100 \pm 0.075^{\mathrm{ab}}$ & $5.253 \pm 0.020^{c}$ & $19.344 \pm 3.374^{\mathrm{a}}$ \\
\hline 无机碳 IC (mg/L) & $13.005 \pm 0.032^{\mathrm{c}}$ & $16.202 \pm 0.291^{\mathrm{bc}}$ & $20.179 \pm 2.703^{\mathrm{bc}}$ & $19.820 \pm 0.001^{\mathrm{ab}}$ & $43.015 \pm 0.061^{\mathrm{a}}$ \\
\hline 硫酸盐 $\mathrm{SO}_{4}^{2-}(\mathrm{mg} / \mathrm{L})$ & $1,582.500 \pm 2.977^{\mathrm{a}}$ & $1,207.558 \pm 100.997^{\mathrm{a}}$ & $837.255 \pm 38.754^{\mathrm{ab}}$ & $897.900 \pm 97.900^{\mathrm{ab}}$ & $117.655 \pm 11.311^{\mathrm{c}}$ \\
\hline 砷 As (mg/L) & $2.407 \pm 0.021^{\mathrm{a}}$ & $2.853 \pm 0.171^{\mathrm{a}}$ & $0.155 \pm 0.012^{\mathrm{b}}$ & $0.180 \pm 0.009^{\mathrm{ab}}$ & $0.003 \pm 0.003^{b}$ \\
\hline 镉 Cd (mg/L) & $0.004 \pm 0.001^{\mathrm{a}}$ & $0.002 \pm 0.001^{\mathrm{a}}$ & $0.002 \pm 0.003^{\mathrm{a}}$ & $0.003 \pm 0.002^{\mathrm{a}}$ & BDL \\
\hline 铜 Cu (mg/L) & $0.017 \pm 0.009^{\mathrm{ab}}$ & $0.032 \pm 0.004^{\mathrm{a}}$ & $0.016 \pm 0.004^{\mathrm{ab}}$ & $0.006 \pm 0.002^{\mathrm{b}}$ & $0.008 \pm 0.001^{\mathrm{b}}$ \\
\hline 铅 $\mathrm{Pb}(\mathrm{mg} / \mathrm{L})$ & $0.060 \pm 0.036^{\mathrm{a}}$ & $0.021 \pm 0.013^{\mathrm{a}}$ & $0.025 \pm 0.030^{\mathrm{a}}$ & $0.043 \pm 0.006^{\mathrm{a}}$ & BDL \\
\hline 锌 Zn (mg/L) & $0.012 \pm 0.001^{\mathrm{ab}}$ & $0.011 \pm 0.004^{\mathrm{b}}$ & $0.009 \pm 0.003^{\mathrm{b}}$ & $2.741 \pm 1.058^{\mathrm{a}}$ & $0.249 \pm 0.057^{\mathrm{a}}$ \\
\hline
\end{tabular}

采样点STW1、STW2和STW3代表尾矿库内沿水流方向从上游到下游的3个采样点, SUSW代表上游渗流水采样点, SDSW代表下游渗流水采 样点。同一行不同字母表示在0.05水平下差异显著 $(P<0.05)$; BDL表示在检出限以下。

The sample sites STW1、STW2 and STW3 represent the three sample sites from upstream to downstream along the flow direction in the tailings reservoir, SUSW represents the upstream seepage water sampling point, and SDSW represents the downstream seepage water sampling point. Different letters in the same column mean significant difference at 0.05 level $(P<0.05)$; BDL is below the detection limit.

表2 十八河尾矿废水中5个采样点真菌群落的丰富度和多样性(平均值土标准误) $(\mathbf{n}=3)$ 。

Table 2 Richness and diversity index of the fungal communities in five sample sites of tailings drainage from Shibahe (mean \pm SE) $(\mathrm{n}=3)$

\begin{tabular}{lllllll}
\hline $\begin{array}{l}\text { 采样点 } \\
\text { Sampling point }\end{array}$ & $\begin{array}{l}\text { 序列数 } \\
\text { Sequence number }\end{array}$ & $\begin{array}{l}\text { OTU个数 } \\
\text { OTUs }\end{array}$ & $\begin{array}{l}\text { Chao1指数 } \\
\text { Chao1 index }\end{array}$ & $\begin{array}{l}\text { Shannon指数 } \\
\text { Shannon index }\end{array}$ & $\begin{array}{l}\text { Simpson指数 } \\
\text { Simpson index }\end{array}$ & $\begin{array}{l}\text { 盖度 } \\
\text { Coverage }\end{array}$ \\
\hline STW1 & $76,565.673 \pm 251.658^{\mathrm{c}}$ & $404.675 \pm 13.436^{\mathrm{c}}$ & $478.636 \pm 25.356^{\mathrm{b}}$ & $5.496 \pm 0.012^{\mathrm{a}}$ & $0.948 \pm 0.001^{\mathrm{a}}$ & $0.999 \pm 0.000^{\mathrm{a}}$ \\
STW2 & $63,438.606 \pm 317.863^{\mathrm{d}}$ & $118.658 \pm 6.813^{\mathrm{e}}$ & $135.338 \pm 10.784^{\mathrm{d}}$ & $2.387 \pm 0.019^{\mathrm{e}}$ & $0.554 \pm 0.005^{\mathrm{d}}$ & $0.998 \pm 0.001^{\mathrm{a}}$ \\
STW3 & $80,413.333 \pm 224.795^{\mathrm{b}}$ & $499.582 \pm 12.000^{\mathrm{a}}$ & $519.275 \pm 16.587^{\mathrm{a}}$ & $5.096 \pm 0.015^{\mathrm{b}}$ & $0.938 \pm 0.001^{\mathrm{b}}$ & $0.997 \pm 0.001^{\mathrm{b}}$ \\
SUSW & $81,207.36 \pm 165.631^{\mathrm{a}}$ & $460.055 \pm 6.084^{\mathrm{b}}$ & $484.696 \pm 11.345^{\mathrm{b}}$ & $2.982 \pm 0.017^{\mathrm{c}}$ & $0.586 \pm 0.004^{\mathrm{d}}$ & $0.996 \pm 0.001^{\mathrm{b}}$ \\
SDSW & $81,094.014 \pm 45.935^{\mathrm{a}}$ & $237.336 \pm 19.759^{\mathrm{d}}$ & $259.418 \pm 11.001^{\mathrm{c}}$ & $2.585 \pm 0.013^{\mathrm{d}}$ & $0.692 \pm 0.002^{\mathrm{c}}$ & $0.999 \pm 0.001^{\mathrm{a}}$ \\
\hline
\end{tabular}

同一列不同字母表示在0.05水平下差异显著 $(P<0.05)$ Different letters in the same column mean significant difference at 0.05 level $(P<0.05)$

\section{3 真菌群落组成与环境参数的相关性}

真菌群落的OTUs和Chao 1指数与 $\mathrm{pH} 、 \mathrm{As}$ 和Cu 浓度显著负相关; Shannon指数与IC浓度显著负相 关, Simpson指数与 $\mathrm{NH}_{4}^{+}$浓度显著负相关; 真菌群 落的丰度(拷贝数)与TOC含量显著正相关(表3)。

圥余分析发现, 在门水平 $\mathrm{pH}$ 和 $\mathrm{NH}_{4}^{+}$对真菌群 落有一定的影响, 但是影响不显著 $(F=1.3, P=$ 0.306) (图4a); 真菌优势纲在不同采样点的分布格 局格局受到 $\mathrm{pH} 、 \mathrm{NH}_{4}^{+}$和IC的影响, 但是影响也不显 著 $(F=5.1, P=0.134)$ (图4b); 真菌优势目在不同采
样点的分布格局主要受到 $\mathrm{IC}$ 和 $\mathrm{pH}$ 的影响 $(F=4.5, P$ $<0.05$ ) (图4c); 真菌优势科在不同采样点的分布格 局主要受到TOC和Cu的影响 $(F=15.4, P=0.051)$ (图4d); 真菌优势属在不同采样点的分布格局主要 受到IC、 $\mathrm{Cu}$ 和 $\mathrm{NH}_{4}^{+}$的影响 $(F=4.5, P<0.05$ ) (图4e)。

\section{4 真菌群落空间结构及其影响因素}

基于Bray-Curtis距离的PCoA排序结果表明真 菌群落在不同采样点的空间结构存在差异 $(R=0.36$, $P<0.05$ ) (图5a)。通过前选择笁选出的对真菌群落 空间分布影响较大的因子是IC和 $\mathrm{pH}$, 但是这 2 个理 


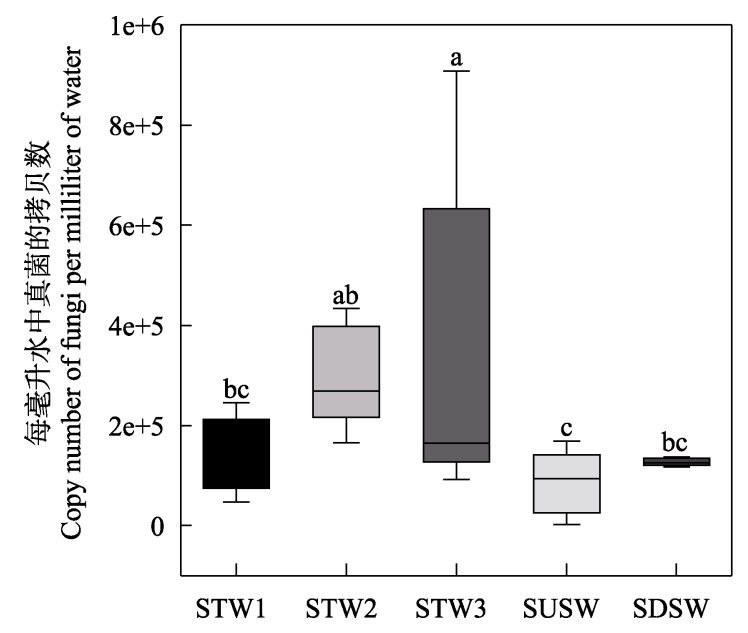

图1 不同采样点真菌群落ITS rDNA拷贝数。STW1、STW2 和STW3表示尾矿库中3个采样点, SUSW和SDSW表示尾矿 库外 2 个渗流水采样点。

Fig. 1 Fungal ITS rDNA copy numbers at the different sample points. STW1, STW2 and STW3 represent three sample sites in the tailings reservoir, SUSW and SDSW represent two seepage water sample sites outside the tailings reservoir.

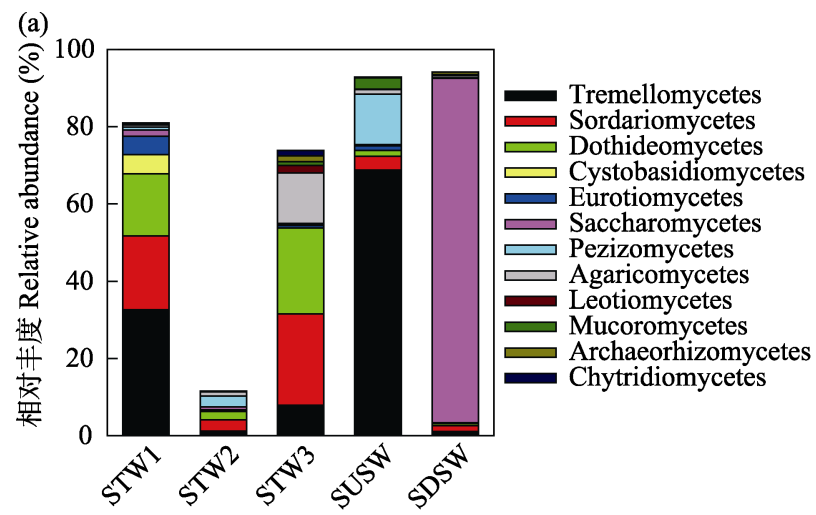

(c)

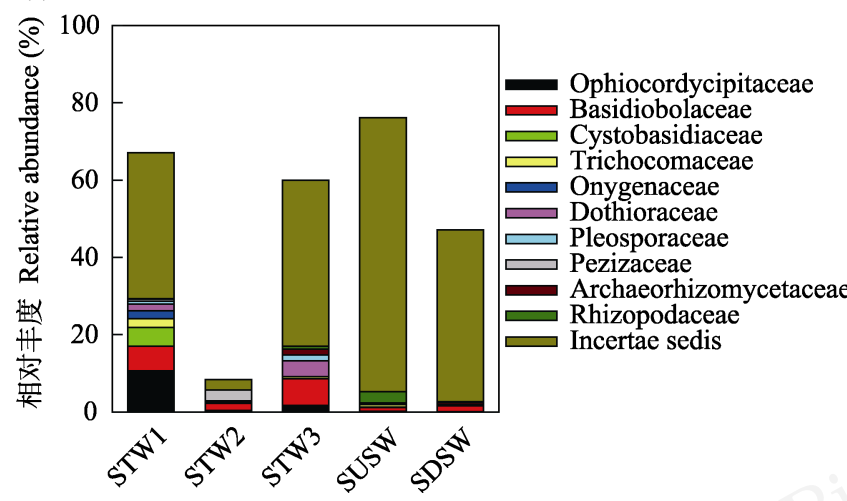

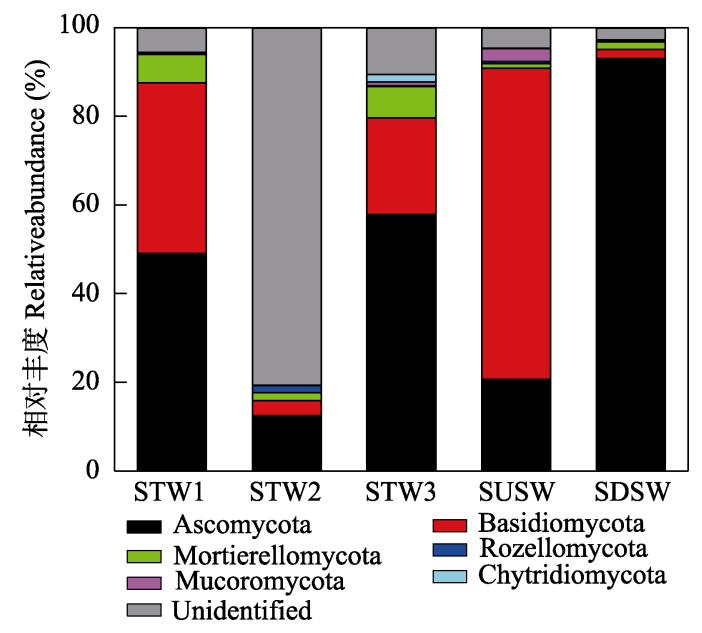

图2 不同采样点真菌群落在门水平的组成。STW1、STW2 和STW3表示尾矿库中3个采样点, SUSW和SDSW表示尾矿 库外 2 个渗流水采样点。

Fig. 2 Fungal community composition of each sampling point at the phyla level. STW1, STW2 and STW3 represent three samplingpoints in the tailings reservoir, SUSW and SDSW represent two seepage water sample sites outside the tailings reservoir.
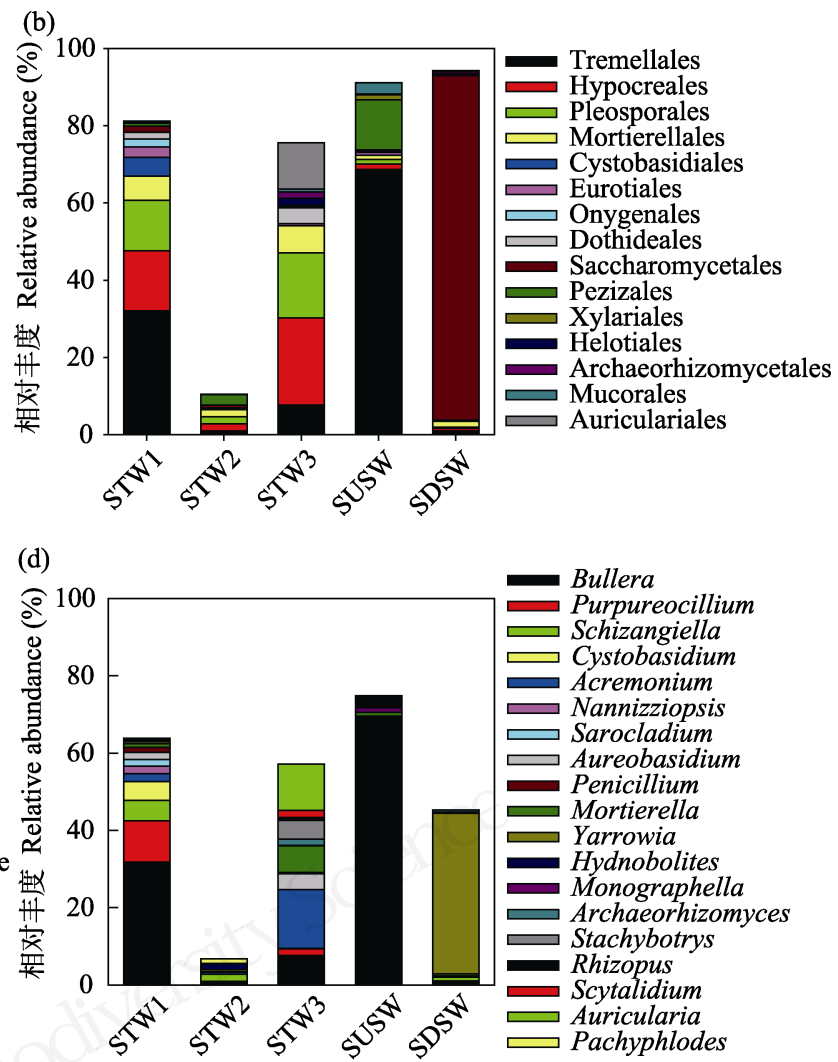

图3 不同采样点真菌群落的优势类群。(a)纲水平; (b)目水平; (c)科水平; (d)属水平。STW1、STW2和STW3表示尾矿库中3 个采样点, SUSW和SDSW表示尾矿库外 2 个渗流水采样点。

Fig. 3 Dominant fungi in different sample sites. (a) Class level; (b) Order level; (c) Family level; (d) Genus level. STW1, STW2 and STW3 represent three samplingpoints in the tailings reservoir, SUSW and SDSW represent two seepage water sample sites outside the tailings reservoir. 

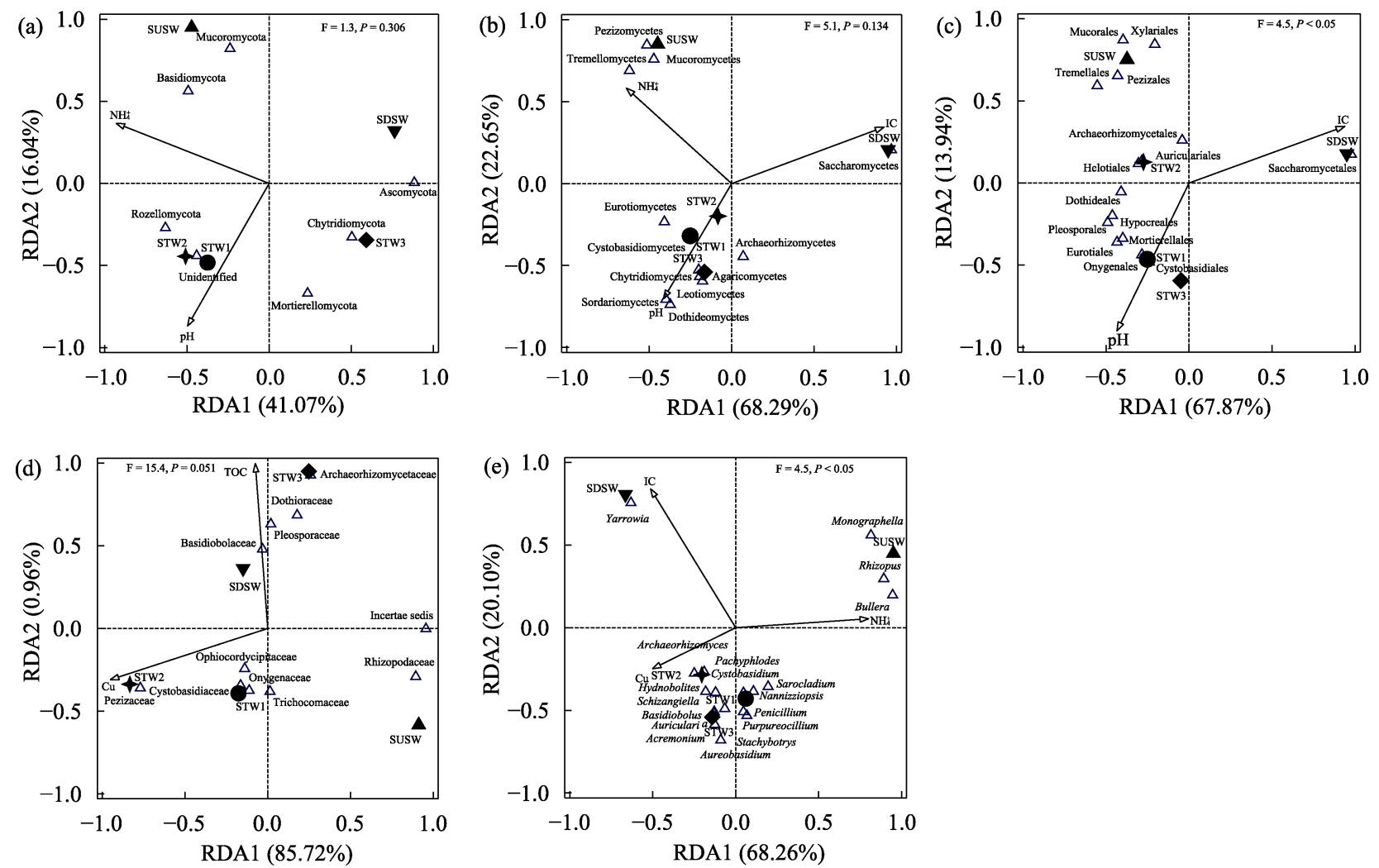

图4 真菌优势类群组成与环境因子的RDA分析。(a)门水平; (b)纲水平; (c)目水平; (d)科水平; (e)属水平。 $\mathrm{NH}_{4}^{+}$: 铵态氮; IC: 无机碳; TOC: 总有机碳; Cu: 铜。

Fig. 4 RDA showing the relationship between environmental parameters and composition of dominant fungal taxa. (a) Phylum level; (b) Class level; (c) Order level; (d) Family level; (e) Genus level. $\mathrm{NH}_{4}^{+}$: Ammonium nitrogen; IC: Inorganic carbon; TOC: Total organic carbon; Cu: Copper.

表3 真菌群落的 $\boldsymbol{\alpha}$ 多样性指数与环境参数的相关性系数 Table 3 Correlation coefficient of $\alpha$ diversity index of fungal communities and environmental parameters

\begin{tabular}{llllll}
\hline $\begin{array}{l}\text { 环境因子 } \\
\text { Parameter }\end{array}$ & & $\begin{array}{l}\text { Chao 1指数 } \\
\text { Chao 1 index }\end{array}$ & $\begin{array}{l}\text { Shannon } \\
\text { index }\end{array}$ & $\begin{array}{l}\text { Simpson } \\
\text { index }\end{array}$ & $\begin{array}{l}\text { 拷贝数 } \\
\text { Copies }\end{array}$ \\
\hline $\mathrm{pH}$ & $-0.706^{* *}$ & $-0.710^{* *}$ & -0.258 & -0.268 & 0.107 \\
$\mathrm{DO}$ & -0.193 & -0.179 & -0.329 & -0.404 & 0.057 \\
$\mathrm{EC}$ & -0.338 & -0.336 & -0.007 & -0.200 & 0.257 \\
$\mathrm{NO}_{3}^{-}$ & -0.132 & -0.129 & 0.346 & 0.293 & 0.493 \\
$\mathrm{NO}_{2}^{-}$ & -0.132 & -0.132 & 0.350 & 0.296 & 0.471 \\
$\mathrm{NH}_{4}^{+}$ & -0.189 & -0.198 & -0.214 & $-0.536^{*}$ & -0.307 \\
$\mathrm{TC}^{+}$ & 0.106 & 0.086 & -0.343 & -0.118 & -0.004 \\
$\mathrm{TOC}^{-106}$ & 0.060 & 0.080 & -0.025 & 0.297 & $0.425^{*}$ \\
$\mathrm{IC}$ & -0.203 & -0.244 & $-0.530^{*}$ & -0.434 & -0.498 \\
$\mathrm{SO}_{4}^{2-}$ & -0.262 & -0.270 & 0.229 & 0.068 & 0.007 \\
$\mathrm{As}$ & $-0.628^{*}$ & $-0.632^{*}$ & -0.186 & -0.261 & 0.104 \\
$\mathrm{Cd}$ & -0.376 & -0.340 & -0.004 & 0.082 & -0.021 \\
$\mathrm{Cu}$ & $-0.616^{*}$ & $-0.579 *$ & -0.400 & -0.239 & 0.346 \\
$\mathrm{~Pb}$ & -0.126 & -0.082 & 0.179 & 0.039 & -0.190 \\
$\mathrm{Zn}$ & 0.179 & 0.161 & -0.050 & -0.146 & -0.350 \\
\hline
\end{tabular}

环境参数代号和单位同表1 Environmental parameters are the same as Table 1. $* P<0.05 ; * * P<0.01$.
化因子对群落空间结构的影响不显著 $(F=2.8, P=$ 0.062 ) (图5b)。零模型分析发现在5个采样点真菌群 落的零偏差值均大于零, 且在 5 个采样点的零偏差 值存在差异, 在SUSW和SDSW中较大, 而在STW1 中最小(图5c)。

不同真菌类群之间存在显著的相互作用关系, 在223个真菌属中有相互关系的属共220个, 连接的 边1,761条，其中只有5条边显示负相关性，占全部 边的 $0.28 \%$ 。在整个网络中共有 6 个独立的模块, 每 个模块的节点和边的个数不同，模块1中的节点个 数最多, 而模块4中边的个数最多(图6)。

\section{3 讨论}

\section{1 尾矿废水中的真菌群落组成和影响因素}

沿废水流动方向水体理化参数形成了明显的 污染梯度, 氮含量沿水流方向逐渐减少而碳含量逐 渐增加, 且库内水的 $\mathrm{pH} 、 \mathrm{EC}$ 和 $\mathrm{SO}_{4}^{2-}$ 显著高于渗流水 (表1)。由于尾矿坝用尾矿砂堆积而成, 因此尾矿坝 

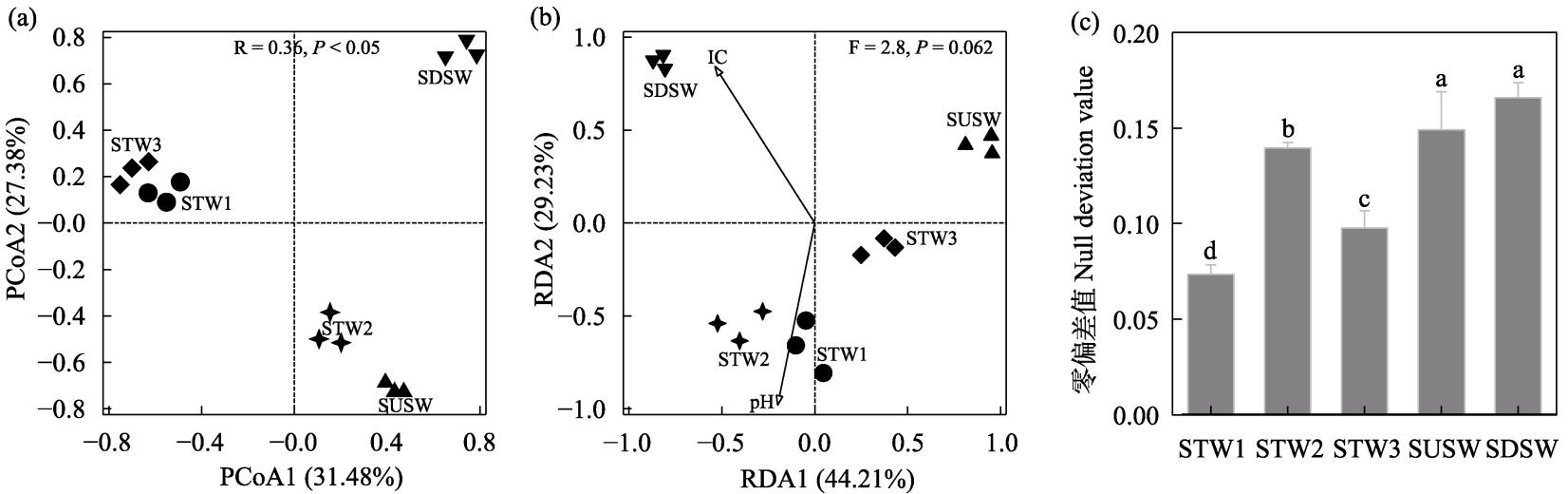

图5 真菌群落空间分布格局及其影响因素。(a)在OTU水平基于Bray-Curtis距离的真菌群落PCoA排序结果; (b)真菌群落结 构与环境因子的冗余分析; (c)基于Bray-Curtis距离的零偏差结果。IC: 无机碳; STW1、STW2和STW3表示尾矿库中3个采样 点, SUSW和SDSW表示尾矿库外2个渗流水采样点。

Fig. 5 Spatial distribution pattern of fungal community structure and its influencing factors. (a) PCoA analysis based on Bray-Curtis similarities of fungal communities at OTU level; (b) RDA showing the relationship between environmental parameters and fungal communities; (c) Null deviation result based on Bray-Curtis distance. IC: Inorganic carbon; STW1, STW2 and STW3 represent three sample sites in the tailings reservoir, SUSW and SDSW represent two seepage water sample sites outside the tailings reservoir.

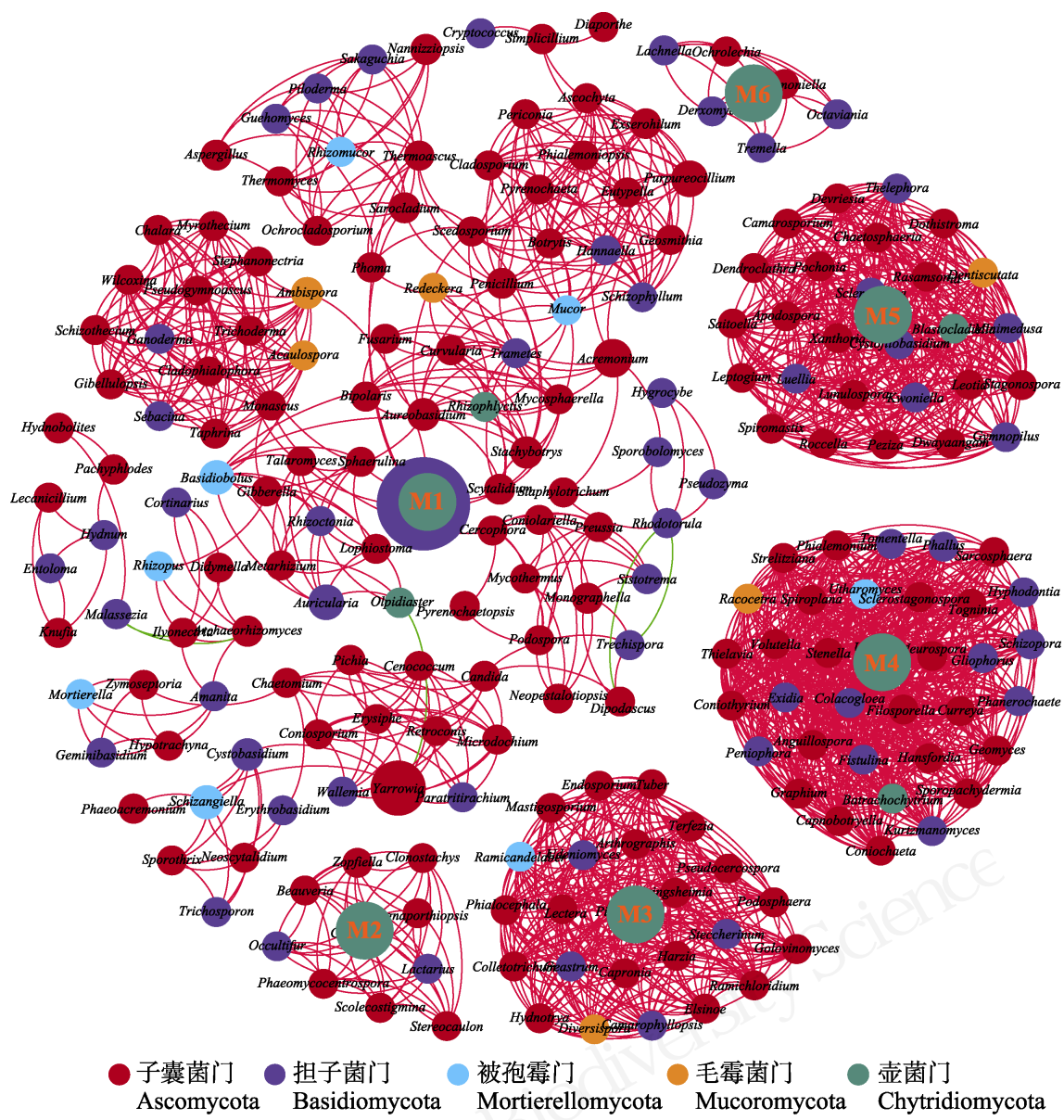

图6 属水平真菌类群间相互作用网络图。每个节点代表一个属, M1-M6代表6个独立模块, 节点大小与丰度成正比, 有显著 相关性的节点通过线连接起来，红线表示正相关，绿线表示负相关。

Fig. 6 Network interactions of fungal groups at genus level. Each circle represents a genus and M1-M6 represent the six independent modules in the network diagram. The sizes of the circles are proportional to the value of abundance. Lines connecting two nodes represent the interactions between them. Red lines represent the positive significant correlations and green lines represent a negative significant correlation. 
体就像一个过滤柱, 尾矿水在渗流过程中含有的部 分重金属和其他污染物被过滤掉, 因此渗流水 SUSW和SDSW中pH、EC、 $\mathrm{NO}_{3}^{-} 、 \mathrm{NO}_{2}^{-}$和 $\mathrm{SO}_{4}^{2-}$ 的含 量低于库内水(STW)。在这样的环境梯度下, 不同 采样点真菌群落的 $\alpha$-多样性(表2)和丰度(图1)存在 差异。比较有意思的是, 在中度污染的STW2采样点 真菌群落的丰富度(OTUs和Chao 1)最小(表2), 这似 乎与“中度干扰假说” (Connell, 1978)相悖。一方面, 可能是由于在STW2采样点重金属Cu和As的浓度相 对较高(表1), 且这两个重金属的浓度与真菌群落的 OTU个数和Chao 1指数显著负相关(表3)。在本研究 中, 虽然已测的每种重金属的浓度都较低(表1), 但 是多种重金属共存时真菌对重金属的耐受性会降 低, 且Cu和Zn共存时其毒性会增加(樊霆, 2009); As 是毒性较强的重金属之一, 在STW1和STW2采样 点As的浓度超过国标要求的工业废水排放标准 $(0.5$ $\mathrm{mg} / \mathrm{L})$, 而较高浓度的As会对微生物群落产生明显 抑制作用, 降低微生物的数量和多样性(杨振兴等, 2015), 从而使As浓度最高的STW2采样点真菌群落 的多样性较低。另一方面, pH也对真菌群落丰富度 有显著影响(表3), 在土壤(Glassman et al, 2017)和 水体(Bier et al, 2015; Sun et al, 2016)中, $\mathrm{pH}$ 梯度对 微生物群落的组成均影响显著。真菌群落生长的最 适pH范围是5.0-8.0 (㚞霆, 2009), 而在我们的研究 区域pH范围是8.014-9.382, 因此对真菌群落的多 样性有显著影响。

在 5 个采样点中, Shannon 和 Simpson 指数在 STW2采样点也最小(表2), 且与 IC和 $\mathrm{NH}_{4}^{+}$浓度显著 负相关(表3)。大多数真菌类群是异养生物, 碳源是 它们的主要能量来源, 因此在IC浓度高的地方真菌 群落聚集引起群落均匀度降低(Jebaraj et al, 2010); 武俊男等(2018)的研究结果表明 $\mathrm{NH}_{4}^{+}$能降低真菌群 落的丰富度和多样性, 这与我们的研究结果一致。

真菌群落的丰度沿水流方向(STW1到STW3)逐 渐增加, 这主要受到有机碳含量变化的影响(表3), 在有机碳含量高的地方真菌群落能获得更多的能 量(Arfi et al, 2012), 因此在STW3采样点真菌群落 的丰度也高。但是, 在有机碳含量最高的SDSW采 样点真菌群落的丰度反而较低(图1)。我们推测可能 的原因是在下游流速缓慢且污染程度较低的渗流 水中藻类的种类和数量较高(遗憾的是我们没有分 析藻类的组成和数量)。
真菌群落的相对丰度不论是在门(图2)还是纲、 目、科和属水平上(图3)均有差异。子囊菌门和担子 菌门是 6 个门中相对丰度最高的 2 个门, 子囊菌门的 相对丰度沿水流方向从STW1到SDSW逐渐增加, 而担子菌门的相对丰度则逐渐减小(图2)。这表明碳 以及其他营养资源稀缺且存在 $\mathrm{pH}$ 和重金属胁迫的 环境有利于菌丝生长缓慢的担子菌门中的真菌类 群生长(Gostinčar et al, 2010)。担子菌门的优势属是 布勒掷狍酵母属和囊担菌属(图3d), 它们对极端环 境都有较强的适应性。布勒掷孢酵母属能很好地利 用烃类等难降解有机碳作为碳源，且通过分泌特殊 种类的 $\beta$-葡糖苷酶来增强对酸碱性的耐受力(魏娜 等, 2014), 因此能在 $\mathrm{pH}$ 值为9.38的碱性尾矿废水中 繁殖增长。囊担菌属对极端环境也有很好的适应性, 徐炜(2014)对深海沉积物和深海热液区的真菌群落 研究发现, 这些样品中均发现有囊担菌属真菌类群, 说明它们可以耐受高温、低氧以及高压的极端环 境。我们的研究结果证实囊担菌属在复合污染的尾 矿废水中也能很好地适应。在可利用资源增加且胁 迫降低的生境中, 利于菌丝体快速生长的子囊菌增 加，促使子囊菌占据更多的空间(Sterkenburg et al, 2015)。许多子囊菌可产生强大的降解酶并能高效利 用底物，可以最大限度地利用现有资源并将其转化 为生物量, 因此在可利用资源较多的下游子囊菌的 丰度较高。

\section{2 真菌群落的分布格局和维持机制}

在不同采样点真菌群落的分布从门到OTU水 平均有变化, 环境因子只在目和属水平对这种格局 的形成有显著影响(图4, 图5)。这是因为从门到 OTU内的物种可能具有非常不同的生态位, 而真菌 的不同功能分类群对环境驱动因素的反应可能不 同(Sterkenburg et al, 2015)。在目水平, 不同采样点 真菌群落分布格局的形成主要受 $\mathrm{pH}$ 和 IC 的影响, 而属水平主要受IC、 $\mathrm{NH}_{4}^{+}$和 $\mathrm{Cu}$ 的影响(图4)。在本 研究中即使重金属的浓度较低, 但在属水平 $\mathrm{Cu}$ 对真 菌群落的影响也是显著的。有研究表明在重金属污 染地区篮选出的一些真菌菌株对重金属有很好的 耐受和富集作用(杨振兴等, 2015)。研究表明对重金 属有较好耐受性的真菌类群主要是青霉菌属 (Penicillium) 、木霉属 (Trichoderma) 和曲霉属 (Aspergillus) (樊霆, 2009; 问华等, 2018), 且这些研 究多数是在稳定可控的室内环境下完成。本研究中 
只有青霉菌属属于优势属 (相对丰度为 $0.002 \%-1.407 \%)$, 相对丰度只在采样点STW1超过 1\% (图3d)。重金属对微生物群落的影响程度因重金 属价态不同而差异明显(杨振兴等, 2015), 这可能也 是重金属Cu对真菌优势属有显著影响的重要原因。 无机碳对真菌群落生长具有积极的促进作用, 可促 进真菌胞外酶的活性, 从而增强其对环境胁迫的抵 抗力(李艳红等, 2013), 而重金属对真菌群落的影响 主要表现在抑制真菌对碳源的利用上, 可降低真菌 对碳源的利用力和利用率(阊华等, 2018), 从而影响 真菌群落的组成和多样性。无机碳和重金属对真菌 群落的这种拮抗作用, 使真菌群落达到稳定的动态 平衡。

在OTU水平上不同采样点的真菌群落虽然具 有不同的空间分布(图5a), 但是通过RDA前选择篮 选出的 2 个因子(pH和IC)的影响并不显著(图5b)。这 表明在尾矿废水这样的生境中真菌群落空间格局 的分布模式，并不是环境因子直接篮选的结果，而 零模型分析结果(图5c)表明种间相互作用是影响群 落空间分布格局的主要因素。在许多生态系统中, 不同物种之间的相互作用对群落分布格局和生态 系统功能至关重要。在生态系统循环过程中, 微生 物类群之间的相互作用似乎比物种丰富度和丰度 以及多样性对生态系统过程和功能的贡献更大 (Lupatini et al, 2014)。在本研究中我们通过网络图 分析发现, 真菌群落的不同属之间存在显著的相互 作用, 且主要表现为正相关性(图6)。表明在尾矿废 水中不同真菌类群之间主要表现为一种互利的相 互作用，从而提高各自的抵抗力。真菌类群之间的 种间相互关系网络形成了大小和复杂程度不同的 6 个模块(图6), 这表明不同物种在生态系统过程中发 挥的功能不同(Zhou et al, 2011), 且各自的作用大小 不同, 一个物种与其关联的物种越多, 表明该物种 越重要。这也说明一个物种在生态系统中是否具有 重要作用与其丰度没有直接的关系, 丰度小的物种 也可能是关键物种, 反之亦然。我们的研究结果表 明, 在复合污染的铜尾矿废水中微生物之间直接和 间接相互作用的复杂网络控制着生态系统的过程 和结果。在这个相互作用的复杂网络中, 在遗传、 形态和功能上具有多样性的真菌类群发挥着多种 作用，它们与水体中其他类群之间既有拮抗作用， 也有协同作用(Grossart et al, 2019)。虽然同种生物
往往由于对资源的竞争普遍存在拮抗作用 (Selbmann et al, 2013), 如水生丝狍菌对其他物种的 生长具有抑制作用, 但是在极端生境中它们却主要 表现为协同作用。这表明，在生态网络中不同微生 物类群之间表现为协同作用还是拮抗作用，会因生 境的不同而发生变化。

综上所述，中条山十八河尾矿废水沿排出方向 从上游到下游形成了污染梯度, 在该生境中真菌群 落的组成在不同采样点明显不同。真菌群落的丰度 沿污染梯度从上游到下游逐渐增加, 这种变化主要 受到TOC浓度变化的影响; $\mathrm{pH}$ 、重金属( $\mathrm{As}$ 和 $\mathrm{Cu}$ )、 IC 和 $\mathrm{NH}_{4}^{+}$是影响真菌群落 $\alpha$-多样性变化的主要因 子。子囊菌门和担子菌门是 2 个主要的优势门, 它们 的相对丰度沿水平方向呈相反的变化趋势, 表明它 们对环境的适应机制不同。担子菌门中的优势属布 勒掷孢酵母属和囊担菌属能够适应高污染生境, 因 此可作为尾矿区域生态恢复的备选菌群。真菌群落 $\beta$-多样性在不同采样点的差异, 主要由种间相互作 用引起。总的来说，在碱性尾矿废水中真菌群落的 $\alpha$-多样性主要受环境因子影响, 而 $\beta$-多样性主要受 种间相关作用影响。

\section{ORCID}

刘晋仙 (D) https://orcid.org/0000-0002-1957-0981 柴宝峰 (D) https://orcid.org/0000-0002-0024-0659 罗正明 (D) https://orcid.org/0000-0003-3719-629X

\section{参考文献}

Aguilera A, González-Toril E (2019) Eukaryotic Life in Extreme Environments: Acidophilic Fungi. pp. 21-38. Springer, Cham.

Arfi Y, Marchand C, Wartel M, Record E (2012) Fungal diversity in anoxic-sulfidic sediments in a mangrove soil. Fungal Ecology, 5, 282-285.

Baker BJ, Banfield JF (2003) Microbial communities in acid mine drainage. FEMS Microbiology Ecology, 44, 139-152.

Bier RL, Voss KA, Bernhardt ES (2015) Bacterial community responses to a gradient of alkaline mountaintop mine drainage in Central Appalachian streams. The ISME Journal, 9, 1378-1390.

Chase JM, Kraft NJB, Smith KG, Vellend M, Inouye BD (2011) Using null models to disentangle variation in community dissimilarity from variation in $\alpha$-diversity. Ecosphere, 2, 1-11.

Connell JH (1978) Diversity in tropical rain forests and coral 
reefs. Science, 199, 1302-1310.

Dreesens LL, Lee CK, Cary SC (2014) The distribution and identity of edaphic fungi in the McMurdo dry valleys. Biology, 3, 466-483.

Fan T (2009) Resistance Mechanism and Enrichment Characteristics of Fungi to Heavy Metals. PhD dissertation, Hunan University, Changsha. (in Chinese with English abstract) [樊霆 (2009) 真菌对重金属的抗性机制和富集 特性研究. 博士学位论文, 湖南大学, 长沙.]

Glassman SI, Wang IJ, Bruns TD (2017) Environmental filtering by $\mathrm{pH}$ and soil nutrients drives community assembly in fungi at fine spatial scales. Molecular Ecology, 26, 6960-6973.

Gostinčar C, Grube M, de Hoog S, Zalar P, Gunde-Cimerman N (2010) Extremotolerance in fungi: Evolution on the edge. FEMS Microbiology Ecology, 71, 2-11.

Grossart HP, Wyngaert SV, Kagami M, Wurzbacher C, Cunliffe M, Rojas-Jimenez K (2019) Fungi in aquatic ecosystems. Nature Reviews Microbiology, 17, 339-354.

He MX, Gao Y, Sun QY (2011) Influence of mine tailings drainage on microbial diversity in the river sediment and paddy soil. Environmental Science, 32, 1778-1785. (in Chinese with English abstract) [贺梦醒, 高毅, 孙庆业 (2011) 尾矿废水对河流沉积物和稻田土壤细菌多样性的 影响. 环境科学, 32, 1778-1785.]

Iram S, Ahmad I, Javed B, Yaqoob S, Akhtar K, Kazmi MR, Badar-uz-Zaman (2009) Fungal tolerance to heavy metals. Pakistan Journal of Botany, 41, 2583-2594.

Jebaraj CS, Raghukumar C, Behnke A, Stoeck T (2010) Fungal diversity in oxygen-depleted regions of the Arabian Sea revealed by targeted environmental sequencing combined with cultivation. FEMS Microbiology Ecology, 71, 399-412.

Li HY, Li DW, He CM, Zhou ZP, Mei T, Xu HM (2012) Diversity and heavy metal tolerance of endophytic fungi from six dominant plant species in a Pb-Zn mine wasteland in China. Fungal Ecology, 5, 309-315.

Li YH, Jiang Y, Wang WJ, Zhang BY (2013) Effect of organic and inorganic carbon on extracellular enzyme activity of acid phosphatase and proteases in three kinds of fungal hyphae. Bulletin of Botanical Research, 33, 404-409. (in Chinese with English abstract) [李艳红, 姜勇, 王文杰, 张 宝友 (2013) 有机碳和无机碳对3种真菌胞外酸性磷酸酶 和蛋白酶活性的影响. 植物研究, 33, 404-409.]

Liu JX, Li C, Jing JH, Zhao PY, Luo ZM, Cao MW, Ma ZZ, Jia T, Chai BF (2018) Ecological patterns and adaptability of bacterial communities in alkaline copper mine drainage. Water Research, 133, 99-109.

Liu JX, Li C, Luo ZM, Wang X, Bao JB, Chai BF (2019) Distribution pattern and diversity maintenance mechanisms of fungal community in subalpine lakes. Environmental Science, 40, 2382-2393. (in Chinese with English abstract)
[刘晋仙, 李軞, 罗正明, 王雪, 暴家兵, 柴宝峰 (2019) 亚高山湖群中真菌群落的分布格局和多样性维持机制. 环境科学, 40, 2382-2393.]

Liu YH, Zhao HX (2000) Advances in theory of disturbance and species diversity preservation. Journal of Beijing Forestry University, 22, 101-105. (in Chinese with English abstract) [刘艳红, 赵惠勋 (2000) 干扰与物种多样性维 持理论研究进展. 北京林业大学学报, 22, 101-105.]

Lupatini M, Suleiman AKA, Jacques RJS, Antoniolli ZI, de Siqueira Ferreira AO, Kuramae EE, Roesch LFW (2014) Network topology reveals high connectance levels and few key microbial genera within soils. Frontiers in Environmental Science, 2, 1-11.

Ma Y, Yu XB (2017) Research progress on bioaccumulation of heavy metals in wastewater by filamentous fungi. Biotechnology Bulletin, 33(10), 59-63. (in Chinese with English abstract) [马燕, 余晓斌 (2017) 丝状真菌生物富 集重金属废水的研究进展. 生物技术通报, 33(10), 59-63.]

Nagano Y, Nagahama T, Hatada Y, Nunoura T, Takami H, Miyazaki J, Takai K, Horikoshi K (2010) Fungal diversity in deep-sea sediments-The presence of novel fungal groups. Fungal Ecology, 3, 316-325.

Newsham KK (2012) Fungi in extreme environments. Fungal Ecology, 5, 379-380.

Orgiazzi A, Lumini E, Nilsson RH, Girlanda M, Vizzini A, Bonfante P, Bianciotto V (2012) Unravelling soil fungal communities from different Mediterranean land-use backgrounds. PLoS ONE, 7, e34847.

Osono T, Ueno T, Uchida M, Kanda H (2012) Abundance and diversity of fungi in relation to chemical changes in arctic moss profiles. Polar Science, 6, 121-131.

Selbmann L, Egidi E, Isola D, Onofri S, Zucconi L, de Hoog GS, Chinaglia S, Testa L, Tosi S, Balestrazzi A, Lantieri A, Compagno R, Tigini V, Varese GC (2013) Biodiversity, evolution and adaptation of fungi in extreme environments. Plant Biosystems, 147, 237-246.

Sterkenburg E, Bahr A, Durling MB, Clemmensen KE, Lindahl BD (2015) Changes in fungal communities along a boreal forest soil fertility gradient. New Phytologist, 207, 1145-1158.

Sun WM, Xiao EZ, Krumins V, Dong YR, Xiao TF, Ning ZP, Chen HY, Xiao QX (2016) Characterization of the microbial community composition and the distribution of Fe-metabolizing bacteria in a creek contaminated by acid mine drainage. Applied Microbiology and Biotechnology, 100, 8523-8535.

Tucker CM, Shoemaker LG, Davies KF, Nemergut DR, Melbourne BA (2016) Differentiating between niche and neutral assembly in metacommunities using null models of $\beta$-diversity. Oikos, 125, 778-789.

Wei N, Xu Q, Zhang N, Li BX (2014) Ballistosporous yeasts: 
A review on systematics, cell differentiation, and their applications. Microbiology China, 41, 1211-1218. (in Chinese with English abstract) [魏娜, 徐琼, 张宁, 李炳学 (2014) 掷狍酵母及其应用研究进展. 微生物学通报, 41, 1211-1218.]

Wu JN, Liu YX, Zhou X, Wang TY, Gao Q, Gao YH, Liu SX (2018) Effects of long-term different fertilization on soil fungal communities in black soil based on the Illumina MiSeq platform. Acta Microbiologica Sinica, 58, 1658-1671. (in Chinese with English abstract) [武俊男, 刘 昱辛, 周雪, 王天野, 高强, 高云航, 刘淑霞 (2018) 基 于Illumina MiSeq测序平台分析长期不同施肥处理对黑土 真菌群落的影响. 微生物学报, 58, 1658-1671.]

Xu W (2014) Fungal Community Structure and Abundance of Deep-sea Sediments from the Pacific Ocean and Hydrothermal Vent Samples from the South Alantic Ocean. $\mathrm{PhD}$ dissertation, Xiamen University, Xiamen. (in Chinese with English abstract) [徐炜 (2014) 太平洋深海沉积物与 南大西洋深海热液区样品的真菌群落结构和丰度研究. 博士学位论文, 厦门大学, 厦门.]

Yan H, Ouyang M, Zhang XH, Duo Y, Zhao XJ, Zhang YJ,
Zheng JF, Liu XY, Pan GX, Bian RJ, Li LQ (2018) Effects of different gradients of heavy metal contamination on soil fungi community structure in paddy soils. Soils, 50, 513-521. (in Chinese with English abstract) [间华，欧阳明， 张旭辉, 多应, 赵熙君, 张玉娇, 郑聚锋, 刘晓雨, 潘根 兴, 市荣军, 李恋卿 (2018) 不同程度重金属污染对稻田 土壤真菌群落结构的影响. 土壤, 50, 513-521.]

Yang ZX, Tian CK, Dang CY, Chang F, Ni JR (2015) Comparative study on $\mathrm{Pb}(\mathrm{II}), \mathrm{Cd}(\mathrm{II}), \mathrm{As}(\mathrm{III}), \mathrm{Cr}(\mathrm{VI})$ resistance characteristics of fungus. Acta Scientiarum Naturalium Universitatis Pekinensis (Natural Science), 51, 667-676. (in Chinese with English abstract) [杨振兴, 田从 魁, 党晨原, 常方, 倪晋仁 (2015) 真菌对重金属 $\mathrm{Pb}(\mathrm{II})$, $\mathrm{Cd}(\mathrm{II}), \mathrm{As}(\mathrm{III})$ 和 Cr(VI)耐受性的比较研究. 北京大学学报 (自然科学版), 51, 667-676.]

Zhou JZ, Deng Y, Luo F, He ZL, Yang YF (2011) Phylogenetic molecular ecological network of soil microbial communities in response to elevated $\mathrm{CO}_{2}$. mBio, 2, e00122-11. 